\title{
Erwiderung auf Dr. A. v. Hayeks Bemerkungen.
}

Von Dr. J. v. Tazson (Budapest).

In Heft 7 dieser Zeitschrift ist unter dem Titel "Bemerkungen zur entwicklungsgeschichtlichen Pflanzengeographie Ungarns " über meine Arbeit „Grundzüge der entwicklungsgeschichtlichen Pflanzengeographie Ungarns" ein Referat ron Hayek erschienen, das sich gegen wesentliche Punkte meiner Darstellung richtet.

Ich suchte in meiner Arbeit die einzelnen Ergebnisse und Ansichten, wenn auch kurz, aber dennoch präzis zu motivieren und jeder, der sich die Mühe nimmt, die Arbeit bei genauer Berücksichtigung der Ergebnisse jener Wissenschaften, auf welchen die entwicklungsgeschichtliche Pflanzengeographie basiert, durchzulesen, wird - glaube ich - bezüglich sämtlicher der angeführten Behauptungen auch die entsprechende Begründung vorfinden.

Es steht mir demnach ferne auf Hayeks Bemerknngen näher einzugehen. Es liegt mir aber umsomehr daran, daß in einer weitverbreiteten wissenschaftlichen Zeitschrift, wie es die nOesterr. Botan. Zeitschrift" ist, dieses von Grund aus irrtümliche Referat Hayeks nicht ohne Korrektur bleibe.

HI a yek geht nämlich von der merkwürdig unrichtigen Behauptung aus, daß ich in meiner Arbeit dahin konkludiert hätte, daß die Vegetation des ungarischen Tieflandes von Norden herstamme.

Meine diesbezüglich in meiner Arbeit öfters und ganz ausdrücklich ausgesprochenen Aeußerungen lauten direkt entgegengesetzt. Unter anderem steht auf S. 49 des Sonderabdruckes: „Somit können die Arten der Steppenflora Westeuropas nicht von den südrussischen Steppen abstammen; sie sind schon von präpleistozänen Zeiten angefangen Ureinwohner der westlichen und besonders südWestlichen Ebenen, Hägelgelände und Gebirge Europas"; oder auf S. 54: „Die Unterzone des Alföldes erhielt ihre Pflanzendecke in der postpleistozänen Zeit vorwiegend aus dem Süden und Südwesten Europas"; und auf S. 50 ist nachdrücklich herrorgehoben, daß eine Annahme, die die Wanderung unserer Pflanzen im Postpleistozän aus dem Norden für möglich darstellt, durchaus keine Berechtigung habe.

Wie Hayek nach all diesen in seiner ganzen Polemik von dem direkt entgegengesetzten Standpunkt ausgehen konnte, ist mir unbegreiflich. Es ist doch bei der häufigen Wiederholung der oben zitierten Auffassung in meiner Arbeit fast unmöglich vorauszusetzen, daß Hayek durch meine Bemerkung auf S. 40, wo doch über die allgemeine vom Norden nach Süden im Tertiär ( $\nabla$ or dem homostatischen“ Zustand) vor sich gegangene Pflanzenwanderung die Rede ist, so arg irregeführt worden wäre.

Fast sämtliche Beweise Hayeks gruppieren sich um seinen erwähnten falschen Ausgangspunkt so, daß es ganz zwecklos wäre, mich mit denselben näher zu befassen. Ich enthalte mich demnach auch auf jene pflanzengeographischen und geologisch-entwicklungsgeschichtlichen Irrtümer, welche in Hayeks Beweisführung vorkommen, näher einzugehen. 
Wenn Hayek außerdem, daß er den Grundgedanken meiner, über 60 Seiten entwickelten pflanzengeographischen Auseinandersetzungen gänzlich falsch auffaßte, sich auch in den Details auffallende Irrtümer zu schulden kommen läßt: z. B. Rindera umbellata für eine der südrussischen Steppen angehörende, östliche Pflanze hält, oder vo n trockenem diluvialem Schotter und Sande "nach dem Zurückweichen des Pliocänmeeres" spricht etc., so wird man es begreifen, daß ich es lebhaft bedauere, daß er sich zur Abfassung dieses Referates bestimmt fühlte, welches die Leser dieser Zeitschrift geradezu irreführte.

\section{Was sind die Phyllokladien der Asparageen?}

(Kritische Bemerkungen zu G. Danĕk, Morphologische und anatomische Studien über die Ruseus-, Danaë- und Semele-Phyllokladien.)

Von Dr. Fritz Zweigelt (Botanisches Laboratorium der Höheren Lehranstalt für Wein- und Obstbau in Klosterneuburg).

(Mit 15 Textabbildungen.)

(Sehluß.1)

\section{Semele.}

Fassen wir vorerst zusammen, was $\mathrm{Daněk} \mathrm{über} \mathrm{das} \mathrm{Phyllokladium}$ sagt: Daněk betont vor allem das Vorhandensein eines kurzen Stieles, mit welchem die Phyllokladien den Stengeln aufsitzen und verweist aut die Analogie mit Danä̈. „Die Verschmälerung, durch welche das Phyllokladium aufsitzt, ist abgeplattet und äußerlich im ganzen vollständig dem gliedförmigen Brachyblast des Phyllokladiums ron Danä̈ ähnlich. Auch im Querschnitte sind die anatomischen Verhältnisse der basalen Partien der Phyllokladien bei den beiden Gattungen gleich .... Je höher hinauf, desto mehr verflacht sich der Zentralzylinder der Gefäßbündel, und in dem ganzen, stielartig verschmälerten Teile des Phyllokladiums tritt zugleich eine Verbreiterung desselben in transversaler Richtung ein. In einer bestimmten Höhe erfolgt aber eine so plötzliche Erweiterung des Phyllokladiums, daß es in ein laubartiges Gebilde übergeht. Die ursprünglich in einem zusammenhängenden Zylinder orientierten Gefäßbündel verteilen und zerlegen sich gleichmäßig in der ganzen Breite des Phyllokladiums und verlaufen parallel seiner ganzen Länge nach. Es handelt sich hier also um den theoretisch aus der Analogie der Gattung Ruscus vorausgesetzten Übergang des axillaren Kurztriebes in ein flaches, terminales Blatt." Im Widerspruch hiezu gesteht Daněk weiter unten, daß der Übergang des stielförmig verschmälerten Unterteiles des Phyllokladiums von Semele androgyna in eine breite Blattspreite nicht so genau charakterisiert sei, wie bei der Gattung Danaë. „Dieser Übergang ist ein ganz allmählicher, und wenn die Gattung Danä̈ nicht existierte, so müßten wir die Phyllokladien von Semele androgyna für anatomisch homogene Gebilde halten." Ganz unerwartet heißt es weiter unten: "Durch Vergleichung:

1) Vgl. Nr. $8 / 9$, S. $313-335$. 